\title{
DERECHO Y POLÍTICAS AMBIENTALES EN EL PAÍS VASCO (SEGUNDO SEMESTRE 2017)
}

\author{
IÑIGO LAZKANO BROTÓNS \\ Profesor colaborador \\ Universidad del País vasco/ Euskal Herriko Unibersitatea
}


Sumario: 1. Aprobación de la nueva estructura orgánica del departamento de medio ambiente, planificación territorial y vivienda. 2. Sistemas de control de los volúmenes de agua del dominio público hidráulico. 3. Implementación de la Red Natura 2000. 4. Medidas de fomento para la protección del medio ambiente.

\section{APROBACIÓN DE LA NUEVA ESTRUCTURA ORGÁNICA DEL DEPARTAMENTO DE MEDIO AMBIENTE, PLANIFICACIÓN TERRITORIAL Y VIVIENDA}

Mediante Decreto 77/2017, de 11 de abril (BOPV, 76, 21 de abril) se ha establecido la nueva estructura orgánica del Departamento de Medio Ambiente, Planificación Territorial y Vivienda (en adelante, DMAPTV). El DMAPTV se compone de tres Viceconsejerías (la de Medio Ambiente, la de Planificación Territorial y la de Vivienda, esta última procedente del antiguo Departamento de Empleo y Políticas Sociales) y una Dirección de Servicios como órgano horizontal que vertebra los procesos transversales del departamento.

La Viceconsejería de Medio Ambiente se estructura en dos Direcciones Generales: la de Administración Ambiental y la de Patrimonio Natural y Cambio Climático. Como órganos colegiados con competencias en materia ambiental adscritos al DMAPTV se hallan la Comisión Ambiental, el Consejo Asesor de Medio Ambiente, el Patronato y el Consejo de Cooperación de la Reserva de la Biosfera de Urdaibai y el Consejo Asesor de Conservación de la NaturalezaNaturzaintza. También están adscritos, entre otros, al departamento el ente público de derecho privado URA (Agencia Vasca del Agua) y la sociedad pública IHOBE S.A. (Sociedad Pública de Gestión Ambiental).

La asignación de funciones que la abundante normativa refiere al órgano ambiental de la Comunidad Autónoma se atribuye de conformidad con la distribución de funciones que se realiza en este decreto de estructura orgánica, correspondiendo a la Viceconsejería de Medio Ambiente aquéllas que no se hallen asignadas específicamente a otro órgano.

\section{SISTEMAS DE CONTROL DE LOS VOLÚMENES DE AGUA DEL DOMINIO PÚBLICO HIDRÁULICO}


Por Orden de 24 de abril de 2017 (BOPV 87, 10 de mayo), del consejero del DMAPTV, se han regulado los sistemas de control de los volúmenes de agua relativos a los aprovechamientos del dominio público hidráulico en las cuencas internas del País Vasco, cualquiera que sea su título habilitante. Se trata de garantizar el respeto a los derechos existentes, medir el volumen de agua realmente utilizado, permitir la correcta planificación y administración de los recursos y asegurar la calidad de las aguas. Esta orden desarrolla lo previsto al efecto por el texto refundido de la Ley de Aguas (Real Decreto Legislativo 1/2001) y, desde el punto de vista competencial, aplica lo dispuesto en el Plan Hidrológico de la parte española de la Demarcación Hidrográfica del Cantábrico Oriental (2015-2021), que dispone que en las cuencas internas del País Vasco los datos registrados serán remitidos a la Agencia Vasca del Agus (URA).

La norma regula los referidos sistemas de medición de caudales y para ello, en primer lugar, aprueba las prescripciones técnicas para su instalación y mantenimiento. Además, establece los procedimientos para registrar las mediciones y determina la obligación de registrar, mantener y comunicar los datos pertinentes. Por último, aborda la regulación de la inspección de los medios de medida instalados por los usuarios.

\section{IMPLEMENTACIÓN DE LA RED NATURA 2000}

Dentro del proceso de implantación de la Red Natura 2000, tras la aprobación de los diferentes decretos de declaración de zonas especiales de conservación (ZEC) y zonas de especial protección de aves (ZEPA), con sus correspondientes medidas de conservación, continúan publicándose las directrices y medidas de gestión de tales lugares, aprobadas por los órganos forales de los territorios históricos. En este período, mediante Resolución 51/2017, de 27 de abril, del Director de la Secretaría del Gobierno y de Relaciones con el Parlamento (BOPV 100, 29 de mayo), se dispone la publicación de las directrices y medidas de gestión de la ZEC Arkamo-GibijoArrastaria (ES2110004) y de la ZEPA Gorobel-Sierra Salvada (ES0000244).

\section{MEDIDAS DE FOMENTO PARA LA PROTECCIÓN DEL MEDIO AMBIENTE}


Diversas han sido las previsiones de ayudas y subvenciones con fines medioambientales que se han convocado en estos últimos meses por el DMAPTV. Así, hay que señalar la convocatoria destinada a subvencionar a empresas para la realización de inversiones destinadas a la protección del medio ambiente (Orden de 12 de septiembre de 2017, BOPV 177, 15 de septiembre); y el programa Eraikal 2017 de ayudas para la implantación de sistemas de gestión, fomento de la calidad constructiva y arquitectónica, de la sostenibilidad y apoyo a la innovación de las empresas del sector de la edificación residencial (Orden de 7 de septiembre de 2017, BOPV 183, 25 de septiembre). Aunque indirectamente relacionadas con el medio ambiente, también ha de destacarse la aprobación de las bases reguladoras y la convocatoria de subvenciones para la integración de la perspectiva de género en el planeamiento municipal y el urbanismo (Orden de 6 de septiembre de 2017, BOPV 173, 11 de septiembre). La referencia es importante puesto que en el documento de avance del instrumento de planeamiento territorial de más alto valor que existe en la CAPV (las Directrices de Ordenación del Territorio), que se hallan en proceso de revisión, se reconoce expresamente la relevancia de esta perspectiva de género en el diseño y gestión de las políticas públicas de ordenación territorial (en aspectos como la movilidad sostenible o el acceso a los recursos en igualdad de condiciones). 